\title{
Racial Disparity in Hypertension Control: Tallying the Death Toll
}

\author{
Kevin Fiscella, MD, MPH $H^{1,2}$ \\ Katbleen Holt, PbD \\ 'Department of Family Medicine, Univer- \\ sity of Rochester School of Medicine and \\ Dentistry, Rochester, New York \\ ${ }^{2}$ Department of Community and Preven- \\ tive Medicine, University of Rochester \\ School of Medicine and Dentistry, Roch- \\ ester, New York
}

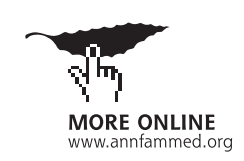

Conflicts of interest: none reported

\section{CORRESPONDING AUTHOR}

Kevin Fiscella, MD, MPH

Departments of Family Medicine,

and Community and Preventive Medicine

University of Rochester School

of Medicine and Dentistry

1381 South Ave

Rochester, NY 14620

Kevin_Fiscella@urmc.rochester.edu

\begin{abstract}
PURPOSE Black Americans with hypertension have poorer blood pressure control than their white counterparts, but the impact of this disparity on mortality among black adults is not known. We assessed differences in systolic blood pressure (SBP) control among white and black adults with a diagnosis of hypertension, and measured the impact of that difference on cardiovascular and cerebrovascular mortality among blacks.
\end{abstract}

METHODS Using SBP measurements from white and black adults participating in the National Health and Nutrition Examination Survey, 1999-2002, we modeled changes in mortality rates resulting from a reduction of mean SBP among blacks to that of whites. Our data source for mortality estimates of blacks with hypertension was a meta-analysis of observational studies of SBP; our data source for reduction in mortality rates was a meta-analysis of SBP treatment trials.

RESULTS The final sample of participants for whom SBP measurements were available included 1,545 black adults and 1,335 white adults. The mean SBP among blacks with hypertension was approximately $6 \mathrm{~mm} \mathrm{Hg}$ higher than that for the total adult black population and $7 \mathrm{~mm} \mathrm{Hg}$ higher than that for whites with hypertension. Within the hypertensive population, a reduction in mean SBP among blacks to that of whites would reduce the annual number of deaths among blacks from heart disease by 5,480 and from stroke by 2,190.

CONCLUSIONS Eliminating racial disparity in blood pressure control among adults with hypertension would substantially reduce the number of deaths among blacks from both heart disease and stroke. Primary care clinicians should be particularly diligent when managing hypertension in black patients.

Ann Fam Med 2008;6:497-502. DOI: 10.1370/afm.873.

\section{INTRODUCTION}

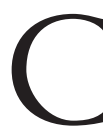

ardiovascular disease, the leading cause of death in the United States, occurs at the highest rate among black Americans. ${ }^{1}$ As a precursor to cardiovascular disease, hypertension is one of the most important contributors to racial disparities in mortality rate. ${ }^{2}$ The age-adjusted prevalence of hypertension is significantly higher among blacks (39\%) than among whites (29\%). ${ }^{3}$ Uncontrolled hypertension has an enormous impact on the health of minorities, ${ }^{1,4}$ accounting for up to one-quarter of all deaths among black adults, primarily from cardiovascular and cerebrovascular causes. ${ }^{5}$

Recent data suggest that among persons under treatment for hypertension, blacks have poorer blood pressure control. ${ }^{3}$ Only a few studies have quantified the effects of racial disparities in health care interventions on the number of deaths among. ${ }^{6,7}$ To our knowledge, none have quantified the impact of disparity in hypertension control on black mortality.

To model the impact of this disparity in hypertension control, we used national data on systolic blood pressure (SBP), mortality data, and published estimates of the relative risk associated with decreases in SBP. Specifically, we calculated the annual numbers of heart and stroke deaths 
that would be avoided or postponed assuming blacks with hypertension had their blood pressure controlled to the same level as whites.

\section{METHODS}

\section{Data Sources}

We used SBP data from the National Health and Nutrition Examination Survey (NHANES) for the years 1999-2002. NHANES is a periodic national survey of the health status of the United States and is designed to yield nationally representative estimates. It includes data from questionnaires, physical examinations, and medical tests. Eligibility criteria for our sample included (1) self-identification as white or black, (2) age of 25 years or older, and (3) diagnosis of hypertension (regardless if treated or not). We also used 2002 US black mortality data for heart disease and stroke, stratified by sex and age. ${ }^{8}$

We estimated the additional risk associated with an elevated SBP based on a meta-analysis of epidemiologic studies of SBP and mortality. This meta-analysis, based on approximately 1 million individuals, estimated the risks, stratified by age and sex, of heart disease and stroke associated with elevated blood pressure. ${ }^{9}$ We estimated the effect of reductions in SBP based on relative risks for heart disease and stroke mortality from a meta-analysis of randomized treatment trials of hypertension. ${ }^{10}$

\section{Estimating Black Mortality Risk From Hypertension}

National mortality rates are known for all black adults (ie, those with and without hypertension), but not for black adults with hypertension. To estimate sex- and age- specific mortality rates for this group, we used NHANES data to derive the mean difference in SBP between blacks with hypertension and all blacks by sex and age. Next, we calculated the relative risk associated with a given difference in SBP between blacks with hypertension and all blacks using the following sex- and age-specific exponential function, derived from a meta-analysis of observational studies of blood pressure and mortality ${ }^{9}$ :

$$
\mathrm{RR}=\mathrm{RR}_{\mathrm{s}}^{(\Delta \mathrm{SBP} / 20)}
$$

where $\triangle$ SBP equals the difference in mean SBP between blacks with a hypertension diagnosis and all blacks aged 25 years or older, and RRs equals the relative risk for heart disease or stroke by age and sex for a standardized $\triangle$ SBP of $20 \mathrm{~mm} \mathrm{Hg}$. The relative risk was then applied to each sex and age category for heart disease and stroke mortality to produce mortality rates adjusted for hypertension. For example, the difference in mean SBP among black men aged 55 to 64 years with hypertension relative to all black men in this age category was $5 \mathrm{~mm} \mathrm{Hg}$ (142 vs $137 \mathrm{~mm} \mathrm{Hg}$ ). This difference represents a relative risk for heart disease mortality of $1.17\left(1 / 0.53^{(5 / 20)}\right)$. The overall mortality rate for black men in this age-group is 605 deaths per 100,000 . Among black men of this age with hypertension, the overall mortality is thus estimated at 708 per $100,000(605 \times 1.17)$. This estimate is conservative because it does not adjust for comorbidity (such as diabetes, hyperlipidemia, or obesity) associated with hypertension. ${ }^{11}$

\section{Estimating Relative Risk From Disparity in SBP}

We estimated the relative risk associated with racial disparity in SBP based on a reduction in the mean SBP for blacks to that of whites in the same sex and age group. We calculated the mean difference in SBP between blacks and whites for each group using NHANES data and used a relative risk for reduction in SBP from a meta-analysis of randomized trials of hypertension treatment. ${ }^{10}$ In that meta-analysis, an $8.3-\mathrm{mm} \mathrm{Hg}$ reduction in SBP was associated with a relative risk of 0.80 (95\% confidence interval [CI], 0.77-0.84) for heart disease mortality and a relative risk of 0.67 (95\% CI, 0.61-0.74) for stroke mortality. We then estimated the relative risk in heart disease mortality for various reductions in SBP using the following formula:

$$
\mathrm{RR}=\mathrm{RR}_{\mathrm{s}} \Delta \mathrm{SBP} / 8.3
$$

where $\triangle$ SBP equals the difference in SBP between blacks and whites matched for sex and age based on NHANES data, and $\mathrm{RR}_{\mathrm{s}}$ is the relative risk for heart disease or stroke standardized to an $8.3-\mathrm{mm} \mathrm{Hg}$ decrease in SBP. We then converted relative risks to relative risk reductions $(R R R=1-R R)$.

\section{Estimating Deaths From Disparity in SBP}

To estimate the number of deaths among blacks that would be postponed or avoided if parity in SBP control were achieved, we multiplied the relative risk reduction by the sex- and age-specific mortality rates (AMR) for blacks adjusted for SBP to obtain the absolute risk reduction. We then multiplied this by the estimated number of blacks $(\mathrm{N})$ in each sex and age group, derived from NHANES data. Our estimate for deaths was thus equal to $\mathrm{RRR} \times \mathrm{AMR} \times \mathrm{N}$.

\section{Statistical Analyses}

The number of persons in each sex and age group and mean SBPs for blacks and whites were derived from NHANES data, weighted to yield national estimates 
using SAS (SAS Institute Inc, Cary, North Carolina). All other calculations were performed using Microsoft Excel (Microsoft Corp, Redmond, Washington).

\section{Sensitivity Analyses}

We conducted a series of sensitivity analyses around key estimates in the model. First, we assessed the effect of assuming a $\pm 30 \%$ black-white difference in SBP. We also assumed a constant difference in SBP across all age-groups using the mean SBP by sex to assess the effect of age distributions on our findings. Next, we used the $95 \%$ CIs surrounding the estimated relatives risks associated with decreases in SBP. ${ }^{10}$ Last, we assumed comparable risk per change in SBP regardless of the source of the estimate, for example, observational data vs treatment data. ${ }^{10}$

\section{RESULTS}

There were 661 black adults and 1,335 white adults with hypertension in the sample and an additional 884 blacks without hypertension. Table 1 shows the number of black men and women in the sample with hypertension in each age-group along with their mean SBP and corresponding 95\% CIs. For men, the mean SBP was $22 \mathrm{~mm} \mathrm{Hg}$ higher in the oldest as compared with the youngest cohort. For women, that difference was $26 \mathrm{~mm} \mathrm{Hg}$.

The differences in mean SBP by age and sex among blacks with hypertension, the entire black adult population, and non-Hispanic whites with hypertension are

Table 1. Mean Systolic Blood Pressures of Blacks With Hypertension by Age and Sex, United States, NHANES 1999-2002

\begin{tabular}{lcc}
\hline $\begin{array}{c}\text { Age-Group, } \\
\text { Years }\end{array}$ & $\begin{array}{c}\text { Mean Pystolic Blood } \\
\text { 2002 }\end{array}$ & $\begin{array}{c}\text { Pressure (95\% Cl), } \\
\text { mm Hg Hotion }\end{array}$ \\
\hline $\begin{array}{l}\text { Men } \\
25-34\end{array}$ & $2,537,000$ & $128(121-135)$ \\
$35-44$ & $2,681,000$ & $135(130-141)$ \\
$45-54$ & $2,116,000$ & $138(133-143)$ \\
$55-64$ & $1,116,000$ & $142(136-148)$ \\
$65-74$ & 693,000 & $139(138-144)$ \\
$\geq 75$ & 436,000 & $150(141-159)$ \\
Women & & $126(121-130)$ \\
$25-34$ & $2,792,000$ & $135(130-141)$ \\
$35-44$ & $3,024,000$ & $142(136-147)$ \\
$45-54$ & $2,460,000$ & $141(136-146)$ \\
$55-64$ & $1,438,000$ & $148(142-153)$ \\
$65-74$ & 977,000 & $152(145-159)$ \\
$\geq 75$ & 849,000 & \\
\hline NHANES = National Health and Nutrition Examination Survey; Cl = confidence \\
interval.
\end{tabular}

shown in Table 2. The mean SBP among black men with hypertension was $6 \mathrm{~mm} \mathrm{Hg}$ higher than that for all black men and $6.5 \mathrm{~mm} \mathrm{Hg}$ higher than that for white men with hypertension. For women, the differences were 6.5 and $8.2 \mathrm{~mm} \mathrm{Hg}$, respectively.

Table 3 shows the annual mortality rates by age and sex for heart disease and stroke for the entire black population, estimates of annual mortality rates for those with hypertension, and estimates for blacks with hypertension assuming racial parity in blood pressure control. Parity in SBP control would reduce annual mortality rates from heart disease and stroke among men by $17 \%$ and $16 \%$, respectively. For women, the reductions would be smaller, $9 \%$ and $14 \%$, respectively

Racial parity in hypertension control would reduce the annual number of deaths from heart disease and stroke by an estimated 5,480 and 2,190 (Table 4). Sensitivity analyses are shown in the Supplemental Appendix (available online at http://www.annfammed. org/cgi/content/full/6/6/497/DC1). Use of 30\% lower or higher estimates for racial differences in SBP yielded a $23 \%$ to $28 \%$ variation in death estimates. Use of a constant (mean SBP difference by race) across age-groups yielded slightly lower estimates for men, but substantially higher estimates for women relative to the base case. In general, use of a constant difference

Table 2. Differences in Mean Systolic Blood Pressures by Age and Sex Between Blacks With Hypertension vs the Black Population and vs Non-Hispanic Whites With Hypertension

\begin{tabular}{lcc}
\hline & \multicolumn{2}{c}{$\begin{array}{c}\text { Difference in Systolic } \\
\text { Blood Pressure, mm Hg }\end{array}$} \\
\cline { 2 - 3 } Glacks With & $\begin{array}{c}\text { Blacks With } \\
\text { Hypertension } \\
\text { vs Entire Black } \\
\text { Population }\end{array}$ & $\begin{array}{c}\text { Hypertension } \\
\text { vs Whites With } \\
\text { Hypertension }\end{array}$ \\
\hline Men & & \\
Age-group, years & & \\
25-34 & 8 & 1 \\
$35-44$ & 9 & 7 \\
$45-54$ & 7 & 9 \\
$55-64$ & 5 & 10 \\
$65-74$ & 1 & 3 \\
$\geq 75$ & 6 & 9 \\
Unweighted mean $\Delta$ & 6.0 & 6.5 \\
Women & & \\
Age-group, years & & 14 \\
$25-34$ & 12 & 13 \\
$35-44$ & 13 & 10 \\
$45-54$ & 12 & 4 \\
$55-64$ & 3 & 4 \\
$65-74$ & 1 & 1 \\
$\geq 75$ & 2 & 8.2 \\
Unweighted mean $\Delta$ & 6.5 & \\
\hline
\end{tabular}


Table 3. Black Mortality Rates by Age, Sex, and Blood Pressure

\begin{tabular}{|c|c|c|c|c|c|c|}
\hline \multirow[b]{2}{*}{ Group } & \multicolumn{2}{|c|}{$\begin{array}{l}\text { Entire Black } \\
\text { Population }{ }^{a}\end{array}$} & \multicolumn{2}{|c|}{$\begin{array}{c}\text { Black } \\
\text { Adults With } \\
\text { Hypertension }\end{array}$} & \multicolumn{2}{|c|}{$\begin{array}{c}\text { With Racial } \\
\text { Parity in Blood } \\
\text { Pressure Controlb }\end{array}$} \\
\hline & $\begin{array}{c}\text { Heart } \\
\text { Disease }\end{array}$ & Stroke & $\begin{array}{c}\text { Heart } \\
\text { Disease }\end{array}$ & Stroke & $\begin{array}{c}\text { Heart } \\
\text { Disease }\end{array}$ & Stroke \\
\hline \multicolumn{7}{|l|}{ Men } \\
\hline \multicolumn{7}{|c|}{ Age-group, years } \\
\hline $25-34$ & 65 & 12 & 85 & 19 & 83 & 19 \\
\hline $35-44$ & 107 & 20 & 146 & 33 & 121 & 24 \\
\hline $45-54$ & 246 & 47 & 314 & 69 & 246 & 44 \\
\hline $55-64$ & 605 & 110 & 709 & 141 & 542 & 87 \\
\hline $65-74$ & 1,192 & 262 & 1,225 & 273 & 1,130 & 236 \\
\hline$\geq 75$ & 3,556 & 864 & 4,047 & 1,017 & 3,177 & 659 \\
\hline Age adjusted & 419 & 90 & 733 & 167 & 603 & 140 \\
\hline \multicolumn{7}{|l|}{ Women } \\
\hline \multicolumn{7}{|c|}{ Age-group, years } \\
\hline $25-34$ & 24 & 7 & 39 & 11 & 7 & 6 \\
\hline $35-44$ & 58 & 17 & 98 & 28 & 89 & 15 \\
\hline $45-54$ & 125 & 36 & 186 & 54 & 142 & 33 \\
\hline $55-64$ & 312 & 70 & 334 & 75 & 277 & 54 \\
\hline $65-74$ & 734 & 181 & 758 & 187 & 680 & 154 \\
\hline$\geq 75$ & 3,438 & 975 & 3,527 & 1,000 & 3,433 & 953 \\
\hline Age adjusted & 400 & 109 & 589 & 159 & 538 & 136 \\
\hline
\end{tabular}

in SBP increased the number of deaths from heart disease by $43 \%$ and that from stroke by $49 \%$. Use of the $95 \%$ upper and lower Cls yielded roughly $8 \%$ to $15 \%$ variations in estimates for heart disease deaths and $18 \%$ to $22 \%$ variations in those for stroke deaths. Last, substitution of age- and sex-specific relative risk values from observational studies for those from treatment studies yielded a $9 \%$ higher estimate of deaths from heart disease and a $21 \%$ lower estimate of deaths from stroke relative to the base case, but very similar estimates of death from heart disease and stroke combined $(7,670$ vs 7,720$)$.

\section{DISCUSSION}

Our findings show that racial disparity in SBP control contributes to nearly 8,000 excess deaths annually from heart disease and stroke among blacks. These findings are fairly robust to changes in key model assumptions. Previous analyses have shown that hypertension is the single largest contributor,

Table 4. Annual Deaths From Heart Disease and Stroke Avoided or Postponed Among Blacks Through Parity in Blood Pressure Control Between Black and White Adults With Hypertension, by Age and Sex

\begin{tabular}{|c|c|c|}
\hline \multirow[b]{2}{*}{ Group } & \multicolumn{2}{|c|}{ Annual No. of Deaths ${ }^{a}$} \\
\hline & Heart Disease & Stroke \\
\hline \multicolumn{3}{|l|}{ Men } \\
\hline \multicolumn{3}{|l|}{ Age-group, years } \\
\hline $25-34$ & 10 & 0 \\
\hline $35-44$ & 120 & 50 \\
\hline $45-54$ & 480 & 170 \\
\hline $55-64$ & 940 & 300 \\
\hline $65-74$ & 420 & 160 \\
\hline$\geq 75$ & 1,450 & 600 \\
\hline Overall & 3,420 & 1,280 \\
\hline \multicolumn{3}{|l|}{ Women } \\
\hline \multicolumn{3}{|l|}{ Age-group, years } \\
\hline $25-34$ & 50 & 20 \\
\hline $35-44$ & 230 & 110 \\
\hline $45-54$ & 420 & 200 \\
\hline $55-64$ & 560 & 210 \\
\hline $65-74$ & 440 & 190 \\
\hline$\geq 75$ & 360 & 180 \\
\hline Overall & 2,060 & 910 \\
\hline Men and women & 5,480 & 2,190 \\
\hline
\end{tabular}

of any medical condition, to racial disparity in adult mortality. ${ }^{2}$ This excess mortality results from a combination of a higher age-adjusted prevalence of hypertension and poorer control of blood pressure among those under treatment. ${ }^{3}$ Our analysis estimated the contribution of just the latter factor to deaths among blacks, but nonetheless, found a substantial impact on the number of deaths in this racial group.

To our knowledge, this study represents the first effort to quantify the toll of racial disparities in blood pressure control. Given the high prevalence of hypertension in blacks, appreciable benefits of blood pressure reduction, and significant disparity in control, it is not surprising that disparity in blood pressure control results in appreciably more deaths than those estimated from other health care disparities, including influenza vaccination, mammography screening, use of $\beta$-blockers after myocardial infarction, treatment of childhood asthma, and diabetes. ${ }^{6,7}$

The causes of racial disparity in blood pressure control are not known. ${ }^{12}$ There are several potential explanations-differences in access to care, clinician management, hypertension severity, and patient adherence. Surprisingly, NHANES data show no racial difference in treatment among all patients with hypertension, suggesting that rates of diagnosis and treatment among blacks in this sample are the same 
as among whites. ${ }^{3}$ Although there is considerable evidence for racial disparity in management of cardiovascular disease, ${ }^{13}$ there is little evidence of racial disparity in treatment of hypertension. Specifically, among those with hypertension, there is no significant difference in rates of drug treatment of hypertension by race. ${ }^{12}$ In addition, some data suggest no difference in clinician adherence to national hypertension treatment guidelines or intensification of antihypertensive treatment by race. ${ }^{14}$

It is possible that blacks have more severe hypertension or respond less favorably to antihypertensive drugs. There is no clear evidence, however, for racial differences in severity, and meta-analyses of treatment trials show a similar response to antihypertensive medication by race, with whites having a slightly greater response to $\beta$-blockers and blacks having a slightly greater response to diuretics. ${ }^{15}$

There is evidence for racial disparity in patient adherence to antihypertensive medication, including studies conducted within the Veterans Administration Health System, where fewer differences in access appear to exist. ${ }^{16-18}$ Differences in adherence by race may be due to affordability of medicines, personal beliefs, anticipated adverse effects, and health literacy that disproportionately affect blacks. ${ }^{18-20}$

Although multiple causes may contribute to racial disparity in blood pressure control, this disparity is not inevitable. Disparity in hypertension control is significantly smaller in the Veterans Administration Health System, where access barriers are fewer. ${ }^{21}$ Little or no disparity in blood pressure control was noted in the treatment arms of 2 large community-based hypertension treatment trials, the Hypertension Detection and Follow-up Program and the Multiple Risk Factor Intervention Trial. ${ }^{22,23}$ It is thus probable that elimination of racial disparity in SBP is an attainable goal, provided sufficient resources are available to discover and address adherence barriers.

The strengths of this study include use of a nationally representative sample to estimate blood pressures among persons with hypertension; use of race-, sex-, and age-specific national mortality rates for heart disease and stroke; and estimates of relative risk associated with SBP derived from meta-analyses.

The limitations of our study merit comment. The sample of hypertensive blacks, although derived from a nationally representative sample, was relatively small. CIs surrounding estimates of blood pressure for specific groups were therefore relatively wide. Because the number of deaths rises exponentially with age, even small variation in estimates of racial disparity in blood pressure among the elderly blacks can yield appreciable changes in estimates. This phenomenon is best illustrated by the results for women. Despite a higher black-white disparity in SBP, our findings showed that elimination of this disparity would reduce deaths more among black men than among black women because the disparity for women is skewed toward younger ages. It is for this reason that use of a constant SBP yielded much higher estimates for women than men. In addition, because of small subgroup sizes, we used an upper age category of 75 years or older. Mean life expectancy at birth in 2004 was 69.5 years for black men and 75.3 years for black women. ${ }^{1}$ Use of this cutoff underestimates the impact of these disparities on deaths among elderly black women. For these reasons, findings that racial disparity in SBP disproportionately affects male mortality should be viewed with caution pending more precise estimates of racial disparity in blood pressure control among men and women of advanced age.

These caveats notwithstanding, our findings suggest that racial disparity in hypertension control contributes appreciably to deaths among blacks from heart disease and stroke. Our analyses highlight the need to more fully understand the causes of these disparities and develop viable strategies to eliminate them, particularly clinician attention to adherence barriers among patients.

To read or post commentaries in response to this article, see it online at http://www.annfammed.org/cgi/content/full/6/6/497.

Key words: Race/ethnicity; blacks; mortality; heart disease; stroke; hypertension; blood pressure; control

Submitted October 28, 2007; submitted, revised, January 29, 2008; accepted March 3, 2008.

Funding support: Funding was provided by the Robert Wood Johnson Foundation and by a grant from the National Heart, Lung, and Blood Institute (R01 HL081066-01A2).

\section{References}

1. Bernstein AB, Makuc DM, Bilheimer L. Health, United States, 2006. Hyattsville, MD: National Center for Health Statistics; 2007.

2. Wong MD, Shapiro MF, Boscardin WJ, Ettner SL. Contribution of major diseases to disparities in mortality. $N$ Engl J Med. 2002;347(20):1585-1592.

3. Ong KL, Cheung BMY, Man YB, Lau CP, Lam KSL. Prevalence, awareness, treatment, and control of hypertension among United States adults 1999-2004. Hypertension. 2007;49(1):69-75.

4. Douglas JG, Bakris GL, Epstein M, et al. Management of high blood pressure in African Americans: consensus statement of the Hypertension in African Americans Working Group of the International Society on Hypertension in Blacks. Arch Intern Med. 2003;163(5):525-541.

5. Cooper RS, Liao Y, Rotimi C. Is hypertension more severe among U.S. blacks, or is severe hypertension more common? Ann Epidemiol. 1996;6(3):173-180. 
6. Fiscella K, Dressler R, Meldrum S, Holt K. Impact of influenza vac cination disparities on elderly mortality in the United States. Prev Med. 2007;45(1):83-87

7. Nerenz D, Vijan S, Lafata EMC. Statistical, Clinical, and Population Health Significance of Racial/Ethnic Disparities in Quality of Care. New York, NY: Commonwealth Fund; 2006.

8. Kochanek KD, Smith BL. Deaths: preliminary data for 2002. Natl Vital Stat Rep. 2004;52(13):1-47.

9. Lewington S, Clarke R, Qizilbash N, Peto R, Collins R, Prospective SC. Age-specific relevance of usual blood pressure to vascular mortality: a meta-analysis of individual data for one million adults in 6 prospective studies. Lancet. 2002;360(9349):1903-1913

10. Law M, Wald N, Morris J. Lowering blood pressure to prevent myocardial infarction and stroke: a new preventive strategy. Health Technol Assess. 2003;7(31):1-94

11. Weycker D, Nichols GA, O'Keeffe-Rosetti M, et al. Risk-factor clustering and cardiovascular disease risk in hypertensive patients. Am J Hypertens. 2007;20(6):599-607.

12. Hertz RP, Unger AN, Cornell JA, Saunders E. Racial disparities in hypertension prevalence, awareness, and management. Arch Intern Med. 2005;165(18):2098-2104.

13. Lillie-Blanton M, Maddox TM, Rushing O, Mensah GA. Disparities in cardiac care: rising to the challenge of Healthy People 2010. J Am Coll Cardiol. 2004;44(3):503-508.

14. Hicks LS, Fairchild DG, Horng MS, Orav EJ, Bates DW, Ayanian JZ. Determinants of JNC VI guideline adherence, intensity of drug therapy, and blood pressure control by race and ethnicity. Hypertension. 2004;44(4):429-434

15. Sehgal AR. Overlap between whites and blacks in response to antihypertensive drugs. Hypertension. 2004;43(3):566-572
16. Hyre AD, Krousel-Wood MA, Muntner P, Kawasaki L, DeSalvo KB. Prevalence and predictors of poor antihypertensive medication adherence in an urban health clinic setting. J Clin Hypertens (Greenwich). 2007;9(3):179-186.

17. Bosworth HB, Dudley T, Olsen MK, et al. Racial differences in blood pressure control: potential explanatory factors. Am J Med. 2006;119(1):70.e9-15.

18. Siegel D, Lopez J, Meier J. Antihypertensive medication adherence in the Department of Veterans Affairs. Am J Med. 2007;120(1):26-32

19. Kennedy J, Coyne J, Sclar D. Drug affordability and prescription noncompliance in the United States: 1997-2002. Clin Ther. 2004;26(4):607-614.

20. Gazmararian JA, Kripalani S, Miller MJ, Echt KV, Ren J, Rask K. Factors associated with medication refill adherence in cardiovascular-related diseases: a focus on health literacy. J Gen Intern Med. 2006;21(12):1215-1221

21. Rehman SU, Hutchison FN, Hendrix K, Okonofua EC, Egan BM. Ethnic differences in blood pressure control among men at Veterans Affairs clinics and other health care sites. Arch Intern Med. 2005;165(9):1041-1047.

22. Five-year findings of the Hypertension Detection and Followup Program. Il. Mortality by race-sex and age. Hypertension Detection and Follow-up Program Cooperative Group. JAMA. $1979 ; 242(23): 2572-2577$

23. Connett JE, Stamler J. Responses of black and white males to the special intervention program of the Multiple Risk Factor Intervention Trial. Am Heart J. 1984;108(3 Pt 2):839-848. 